\title{
Evaluated the Success of Fractionally Integrated-GARCH Models on Prediction Stock Market Return Volatility in Gulf Arab Stock Markets
}

\author{
Heitham Al-Hajieh ${ }^{1}$ \\ ${ }^{1}$ Department of Finance, King Abdulaziz University, KSA \\ Correspondence: Heitham Al-Hajieh, Department of Finance, King Abdulaziz University, KSA. E-mail: \\ aa4119@hotmail.co.uk
}

Received: April 27, 2017

Accepted: May 26, 2017

Online Published: June 20, 2017

doi:10.5539/ijef.v9n7p200

URL: https://doi.org/10.5539/ijef.v9n7p200

\begin{abstract}
:
This paper evaluated the different Fractionally Integrated-GARCH Models (FIGARCH BBM's, FIGARCH Chung, FIEGARCH, FIAPARCH BBM's, FIAPARCH Chung, and HYGARCH). This is the first research to use six different Fractionally Integrated-GARCH Models. Most research compares one of Fractionally Integrated-GARCH Models with the traditional GARCH, EGARCH, GJG-GARCH, IGARCH, and APGARCH. To do so, daily returns of Gulf Cooperation Council (GCC) Stock Markets analyzed, covering the period 1995 to 2015. Both the Superior Predictive Ability and the Model Confidence Set tests were used to identify the best fitting models of each country. The results reveal that FIGARCH BBM is the best fitting model for UAE, KSA, and Bahrain. FIEGARCH is the best fitting model for Kuwait. FIGARCH Chung is the best fitting model for Qatar. Only the results for Oman were mixed between FIGARCH BBM and FIAPARCH BBM models.
\end{abstract}

Keywords: fractionally Integrated-GARCH, forecasting, evaluating, Gulf Cooperation Council (GCC), mean squared error, superior predictive ability

\section{Introduction}

Despite extensive literature on the long-memory and persistence effects in stock market returns in the developed countries, little has been done on emerging market asset prices. In general, the Middle East and North Africa (MENA) equity markets such as the GCC countries are typically much smaller, less liquid, and more volatile than the well-known world financial markets (Harvey, 1995). There is also more evidence that these markets are less efficient in terms of information, due to poor-quality information, high trading costs, and less competition, and their industrial organization is often quite different from that in developed economies (Al-Hajieh et al., 2011).

Since the global financial crisis of 2007-2009 and subsequent shocks in the oil price, GCC market authorities have applied significant economic reforms, such as:

1). Raising of their banking sector effectiveness,

2). Developing their local stock markets,

3). Supporting efficient corporate debt markets,

4). Contribution suitable conditions for the introduction of a range of derivative financial tools and motivating private institutional investments.

These reforms together with the accumulation of wealth and the high increase of liquidity have contributed to the emergence of formal trading of stocks and establishing stock markets in the region. On the other hand, stock markets in GCC countries have become an alternative source for global portfolio diversification and offer international investors new opportunities to increase and improve their portfolios (Al-Hajieh, 2015).

This main aim of this research is, to examine the presence of fractional integration, or long memory and persistence effects in the daily returns of GCC markets covering the period from 1995 to 2015, by applying six Fractionally Integrated-GARCH Models, namely FIGARCH BBM's, FIGARCH Chung, FIEGARCH, FIAPARCH BBM's, FIAPARCH Chung, and HYGARCH. Then these models are evaluated in order to identify the more applicable model for each country.

The remainder of the paper is organized as follows. Section 2 presents the literature review and section 3 
presents the methodology. Section 4 describes the data and debates the preliminary results. Section 5 presents the empirical findings and, finally, Section 6 concludes.

\section{Literature}

The long memory literature constructed mainly on the estimation of the Hurst exponent. Nevertheless, other approaches were appeared to account for persistence, the Autoregressive Conditional Heteroscedasticity (ARCH) models is one of these approaches that used in recent literature to examine long memory behavioral of stock market return.

An ARCH model is difference than Hurst approach as long memory is estimated by considering the historical variation of volatility into account. Furthermore, Baillie et al. (1996) presented the Fractionally Integrated GARCH (FIGARCH) that more expandable than the traditional Generalized ARCH (GARCH) or Integrated GARCH (IGARCH) models. Additionally, number of extensions of FIGARCH models have been developed to count for dynamics in volatility, such as, the FIEGARCH model introduced by Bollerslev and Mikkelsen (1996), and the FIAPARCH model to count for symmetric and asymmetric stock market returns.

Due to the theoretical and practical importance of the dynamics volatility concern, widespread researches have been done to analyze long memory behavioral of financial markets over the world. For example, Bentes and Ferreira (2013) use FIGARCH BBM model to examine the long memory behavioral in the stock market returns of Portugal, Italy, Greece, Ireland, and Spain, for the period from 1998 to 2013. The results show that long memory is most noticeable for Italian and least for Greek returns. This finding indicates that the effect of shocks in the Italian stock market tend to have longer durations than in the other markets.

Kumar, D. (2013) examines asymmetry and long memory properties in the volatility of Portugal, Italy, Greece, Ireland, and Spain, over the period 2003 to 2011 using the ARFIMA-GARCH, IGARCH, FIGARCH, FIGARCH, EGARCH and FIEGARCH for comparative purpose. The results show that the ARFIMA-FIGARCH model specification is better able to capture the long memory property of conditional volatility than the conventional GARCH and IGARCH models.

Furthermore, Bentes (2014) used the FIGARCH BBM model to studies the long memory behavioral of the G7's major stock market indices, period cover from 1999 to 2009. The results show evidence of long memory in the conditional variance, which is more marked for Germany, Italy and France. However, Japan was found to be less persistent.

A number of other studies have examined volatility in MENA countries like the GCC. For example, Aloui and Hela ben (2014) examined the GCC, that is KSA, Bahrain, Kuwait, Qatar, Oman, and UAE stock markets index for the period 2003 to 2013 to identify whether long memory (LM), asymmetry and structural breaks in stock market returns matter when forecasting the value at risk $(\mathrm{VaR})$ and expected shortfall $(\mathrm{ES})$ for short and long trading positions. They found that only two markets, namely Saudi Arabia and Oman, exhibit LM in both conditional mean and variance. The stock returns for the remaining GCC markets, however, do not possess LM property in their conditional means, but their conditional variances exhibit LM. Furthermore, for out-of-sample forecasting, the FIAPARCH model with skewed Student-t distributions provides the best predictive ability.

Boubaker and Sghaier (2015) investigated MENA stock markets, that is Bahrain, Egypt, Jordan, Kuwait, Oman, Qatar, Saudi Arabia and United Arab Emirates (UAE) over the period from 2005 to 2015 using FIAPARCH by implementing a wavelet theory. The empirical results provide strong evidence of a nonlinear deterministic trend, daily seasonal long-range dependence and short dependence in the selected MENA stock market returns, as well as asymmetric time-varying conditional volatility.

Al-Hajieh (2015) investigates the volatility for 17 different indices (Abu Dhabi, Bahrain, Bangladesh, Dubai, Egypt, Indonesia, Jordan, Kuwait, Lebanon, Malaysia, Morocco, Oman, Pakistan, Qatar, Saudi Arabia, Tunisia, and Turkey). He found that, the conditional variance exhibits reasonably long persistence of volatility for all countries, and stock market investors respond differently to bad news compared to good news in all countries with the exception of Tunisia, Morocco, Lebanon, Bahrain and Oman.

Assaf (2016) investigated structural breaks (like financial crisis 2008) and long memory in a group of MENA equity markets (Bahrain, Egypt, Jordan, Kuwait, Lebanon, Morocco, Oman, Qatar, Tunisia and the UAE) for the sample period from 2005 to 2012. He employs modified rescaled range analysis (R/S), and rescaled variance test $(\mathrm{V} / \mathrm{S})$. The results confirm that there was evidence of a weakening in the long memory effects for the second sub-period only, but not for the first sub-sample and the full sample.

Despite extensive literature on the long-memory properties of stock market prices in the developed countries, none of the previous studies evaluated the difference models of Fractionally Integrated-GARCH Models 
(FIGARCH BBM's, FIGARCH Chung, FIEGARCH, FIAPARCH BBM's, FIAPARCH Chung, and HYGARCH). In most research, they compare one of the Fractionally Integrated-GARCH Models with the traditional GARCH, EGARCH, GJG-GARCH, IGARCH, and APGARCH. This research aims to fill the gap in the literature by comparing these models.

\section{Methodology}

The main goals of using Fractionally Integrated-GARCH models is proficient to explain and represent the observed historical dependencies in financial market volatility, for example the FIGARCH model permits only a slow hyperbolic rate of decay for the lagged squared or unconditional innovations in the conditional variance function. FIGARCH model can adjust the time dependence of the variance and a leptokurtic unconditional distribution for the stock returns with long memory behaviour for the conditional variances.

This research assess six Fractionally Integrated-GARCH Models, namely; FIGARCH BBM's, FIGARCH Chung, FIEGARCH, FIAPARCH BBM's, FIAPARCH Chung, and HYGARCH.

The different models are successively assessed by: (i) review of model parameters and (ii) an assessment of model forecasting performance. For deliberation, the latter employs a series of tests included the Superior Predictive Ability (SPA) test Hansen (2005) and the Model Confidence Set (MCS) test (Hansen, et al. 2011).

The forecast-based tests employ a 'loss-function' to recognize the most efficient model. The loss function can be assessed using Mean Squared Error (MSE) and Mean Absolute Deviation (MAD) statistics. SPA distinguishes the 'best' model in relations of predictive capability and MCS classifies the 'best' model set.

\subsection{FIGARCH BBM's}

To imitate the activities of the correlogram of the detected volatility, Baillie, et al. (1996) (BBM) presented the Fractionally Integrated GARCH (FIGARCH) model by exchanging the first difference operator of GARCH equation's by $(1-L)^{d}$, therefore, the conditional variance of the FIGARCH $(\mathrm{p}, \mathrm{d}, \mathrm{q})$ is given by:

$$
\sigma_{t}^{2}=\omega[1-\beta(L)]^{-1}+\left\{1-[1-\beta(L)]^{-1} \phi(L)(1-L)^{d}\right\} \varepsilon_{t}^{2}
$$

where:

$$
\omega[1-\beta(L)]^{-1}=\omega^{*}
$$

$$
\left\{1-[1-\beta(L)]^{-1} \phi(L)(1-L)^{d}\right\} \varepsilon_{t}^{2}=\lambda(L)
$$

Or

$$
\sigma_{\mathrm{t}}^{2}=\omega^{*}+\sum_{\mathrm{i}=1}^{\infty} \lambda_{\mathrm{i}} \mathrm{L}^{\mathrm{i}} \varepsilon_{\mathrm{t}}^{2}=\omega^{*}+\lambda(\mathrm{L}) \varepsilon_{\mathrm{t}}^{2}, \text { with } 0 \leq \mathrm{d} \leq 1 .
$$

It is fairly easy to show that $\omega>0, \beta_{1}-\mathrm{d} \leq \phi_{1} \leq \frac{2-d}{3}$ and

$d\left(\phi_{1}-\frac{1-d}{2}\right) \leq \beta_{1}\left(\phi_{1}-\beta_{1}+d\right)$ are sufficient to ensure that the conditional variance of the FIGARCH $(1, \mathrm{~d}, 1)$ is positive almost surely for all $t$.

\subsection{FIGARCH Chung}

Chung (1999) classified the BBM model drawback. For example, there is a structural discrepancy in the BBM measurement. Equivalent with the ARFIMA framework of the conditional mean equation is incomplete, causing difficultly in interpretations of the estimated parameters. Definitely the fractional differencing operator applies to the constant term in the mean equation (ARFIMA) while it does not in the variance equation (FIGARCH). Chung (1999) suggested a little different process:

$$
\phi(L)(1-L)^{d}\left(\varepsilon_{t}^{2}-\sigma^{2}\right)=[1-\beta(L)]\left(\varepsilon_{t}^{2}-\sigma_{t}^{2}\right)
$$

where $\sigma^{2}$ is the unconditional variance of $\varepsilon_{\mathrm{t}}$. Applying variance targeting to this model implies replacing $\sigma^{2}$ with its sample counterpart.

If we keep the same definition of $\lambda(L)$ as in the FIGARCH BBM equation, we can formulate the conditional variance as:

$$
\sigma_{t}^{2}=\sigma^{2}+\left\{1-[1-\beta(L)]^{-1} \phi(L)(1-L)^{d}\right\}\left(\varepsilon_{t}^{2}-\sigma^{2}\right)
$$

or

$$
\sigma_{t}^{2}=\sigma^{2}+\lambda(L)\left(\varepsilon_{t}^{2}-\sigma^{2}\right)
$$

Chung (1999) shows that $\sigma^{2}>0$ and $0 \leq \phi_{1} \leq \beta_{1} \leq \mathrm{d} \leq 1$ is sufficient to ensure positivity, when $\mathrm{p}=\mathrm{q}=1$.

$\lambda(L)$ is an infinite summation which, in practice, has to be truncated. BBM propose to truncate $\lambda(L)$ at 1000 lags and replace the unobserved $\varepsilon_{\mathrm{t}}^{2}$ 's by the empirical counterpart of $\mathrm{E}\left(\varepsilon_{\mathrm{t}}^{2}\right)$, i.e. $1 / T \sum_{t=1}^{T} \hat{\varepsilon}_{\mathrm{t}}^{2}$. Contrary to BBM, Chung proposes to truncate $\lambda(L)$ at the size of the information set $(\mathrm{T}-1)$ and to initialize the unobserved $\left(\varepsilon_{t}^{2}-\right.$ 
$\left.\sigma^{2}\right)$ at 0 (this quantity is small in absolute values and has a zero mean).

\subsection{FIEGARCH}

Bollerslev and Mikkelsen (1996) have revealed that the integrated fractional models are more appropriate to fit with the returns of Standard and Poor (S\&P) 500. More specifically, they have found that the slightly integrated models would yield better estimates than the GARCH (p, q) as well as the IGARCH (p, q) models, and that the FIEGARCH specifications are more appropriate than the FIGARCH process. In this respect, Bollerslev and Mikkelsen (1996) confirm that the FIEGARCH model proves to be more reliable and consistent, since it helps provide a direct shock-persistence as well as a shock asymmetric volatility measurement and gains more ground than the EGARCH and the IEGARCH models.

Bollerslev and Mikkelsen (1996) extended GARCH and EGARCH models to take account of the long memory autoregressive polynomial factoring

$[1-\beta(L)]=\phi(\mathrm{L})(1-\mathrm{L})^{\mathrm{d}}$, where all the roots of $\phi(\mathrm{z})=0$ lie outside the unit-root circle. The FIEGARCH $(\mathrm{p}, \mathrm{d}$, q) is, therefore, specified:

$$
\log \left(\sigma_{t}^{2}\right)=\omega+\phi(L)^{-1}(1-L)^{-d}[1+\alpha(L)] g\left(z_{t-1}\right)
$$

\subsection{FIAPGARCH}

Tse (1998) proposed the fractionally integrated APARCH (FIAPARCH) model, which extended the FIGARCH model by adding the function $\left(\left|\varepsilon_{i}\right|-\gamma_{i} \varepsilon_{i}\right)^{\delta}$ of the APARCH model to capture the asymmetry and the long-memory properties in the conditional variance. The FIAPARCH can be expressed as:

$$
\sigma_{t}^{\delta}=\alpha_{0}-[1-\beta(L)]^{-1}+\left[1-\phi(L)[1-\beta(L)]^{-1}(1-L)^{d}\right]\left(\left|\varepsilon_{i}\right|-\gamma_{i} \varepsilon_{i}\right)^{\delta}
$$

The FIAPARCH model can capture some well-known stylized properties of volatility:

- for $0<\mathrm{d}<1$ volatility displays the long-memory property;

- when $\gamma>0$, negative shocks give rise to higher volatility than positive shocks;

- the power term $\delta$ of returns for the predictable structure in the volatility pattern should be determined by the data; and

- $\quad$ the FIAPARCH model also nests the FIGARCH model when $\delta=2$ and $\gamma=0$

Thus, the FIAPARCH model is superior to the FIGARCH model because it can captures asymmetry and long memory in the conditional variance (Tse, 1998). And the parameters can be estimated using two methods whether it be by the Baillie et al. (1996) process or the Chung (1999) as explained previously.

\subsection{HYGARCH}

Davidson (2004) proposed a hyperbolic GARCH (HYGARCH) model, to overcome a limitation of the FIGARCH process, which always has infinite variance. This limits its application. Therefore, Davidson (2004) proposed a hyperbolic GARCH (HYGARCH) model, to overcome this drawback.

$$
\begin{gathered}
y_{t}=\varepsilon_{t} \sqrt{h_{t}} \\
h_{t}=\frac{\gamma}{\beta(1)}+\left\{1-\frac{\delta_{H}(B)}{\beta(B)}\left[1-\phi+\phi(1-B)^{d}\right]\right\} y_{t}^{2}
\end{gathered}
$$

where $\phi>0$. This model will reduce to the FIGARCH model if $\phi=1$, and the variance of $y_{t}$ is finite when $1-(1-\phi) \delta_{H}(1) / \beta(1)<1$. Note that the polynomial $\delta^{*}(x)$ in (1) has a unique root on $\mathrm{R}+$, say $1 / \phi$, and in terms of $\phi$ the conditional variance of the GARCH model has the form:

$$
\begin{gathered}
h_{t}=\frac{\gamma}{\beta(1)}+\left\{1-\frac{\delta_{H}(B)}{\beta(B)}[1-\phi B]\right\} y_{t}^{2} \\
=\frac{\gamma}{\beta(1)}+\left\{1-\frac{\delta_{H}(B)}{\beta(B)}[1-\phi+\phi(1-B)]\right\} y_{t}^{2}
\end{gathered}
$$

i.e. we can arrive at the HYGARCH model after replacing $(1-\mathrm{B})$ with $(1-B)^{d}$ in the above equation; see $\mathrm{Li}$ et al. (2011). Note that the coefficients $\pi_{j} \mathrm{~s}$ in (2) have more persistence as $d$ decreases, and the memory of $(1-B)^{d}$ is continuous at $d=1$ (Davidson, 2004). By letting $0<d \leq 1$, the HYGARCH model can then be extended to encompass the common GARCH model with geometric memory (Li et al., 2011). Robinson and Zaffaroni (2006) also considered a hyperbolic GARCH model. However, it has not attracted much attention so far. Further discussion can be found in Conrad and Haag (2006), Conrad (2010), and Li et al. (2015).

Fascinatingly, the HYGARCH nests the FIGARCH when $\alpha=1$ (or equivalently when $\log (\alpha)=0$ ) and the process is stationary when $\alpha<1$ (or equivalently when $\log (\alpha)<0$ ) in which case the GARCH element detects the 
typical covariance stationarity restrictions (see Davidson, 2004 for more details).

\section{Data Preliminary}

The dataset used in this research consists of the daily closing prices of the Stock markets in GCC markets (Bahrain, UAE, Kuwait, Oman, Qatar, and Saudi Arabia). The data was collected from the Thomson- Reuters Eikon database and includes of a total of 3149 trading days for Bahrain, 3718 trading days for UAE, 4580 trading days for Kuwait, 4862 trading days for Oman, 2194 trading days for Qatar, and 4554 trading days for Saudi Arabia. Daily returns were computed as the log-difference of the daily closing prices.

Figure 1, 2 illustrates the price index and the daily returns of Bahrain, UAE, Kuwait, Oman, Qatar, and Saudi Arabia for the sample period under deliberation. It can be detected that all series exhibit volatility clustering effects as periods of high volatility are pursued by periods of low volatility.

Furthermore, there is also evidence of synchronized behavior among all return series, with the great majority of peaks and troughs visibly occurring at the same time. This may suggest that the series are somehow correlated or that there is some kind of association among them. However, analyzing the extent to which these returns are correlated goes beyond the scope of this paper and constitutes another topic of research.
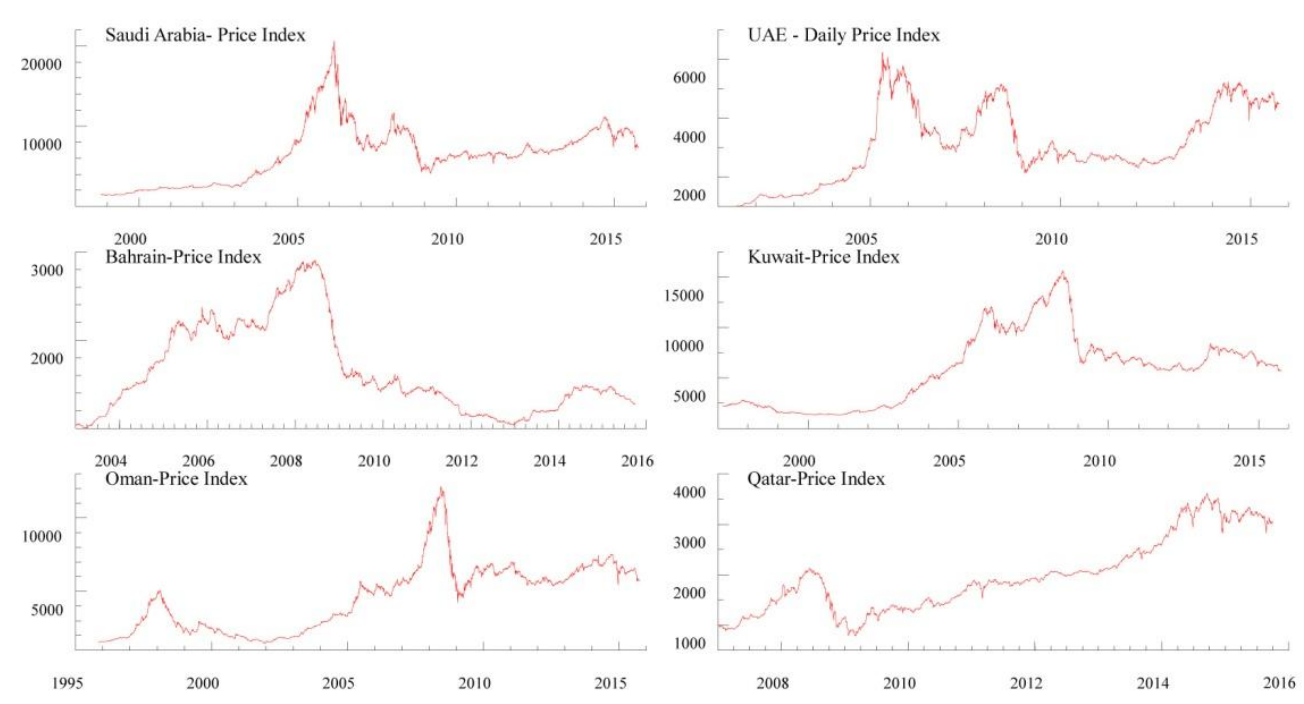

Figure 1. Daily price index for all GCC countries
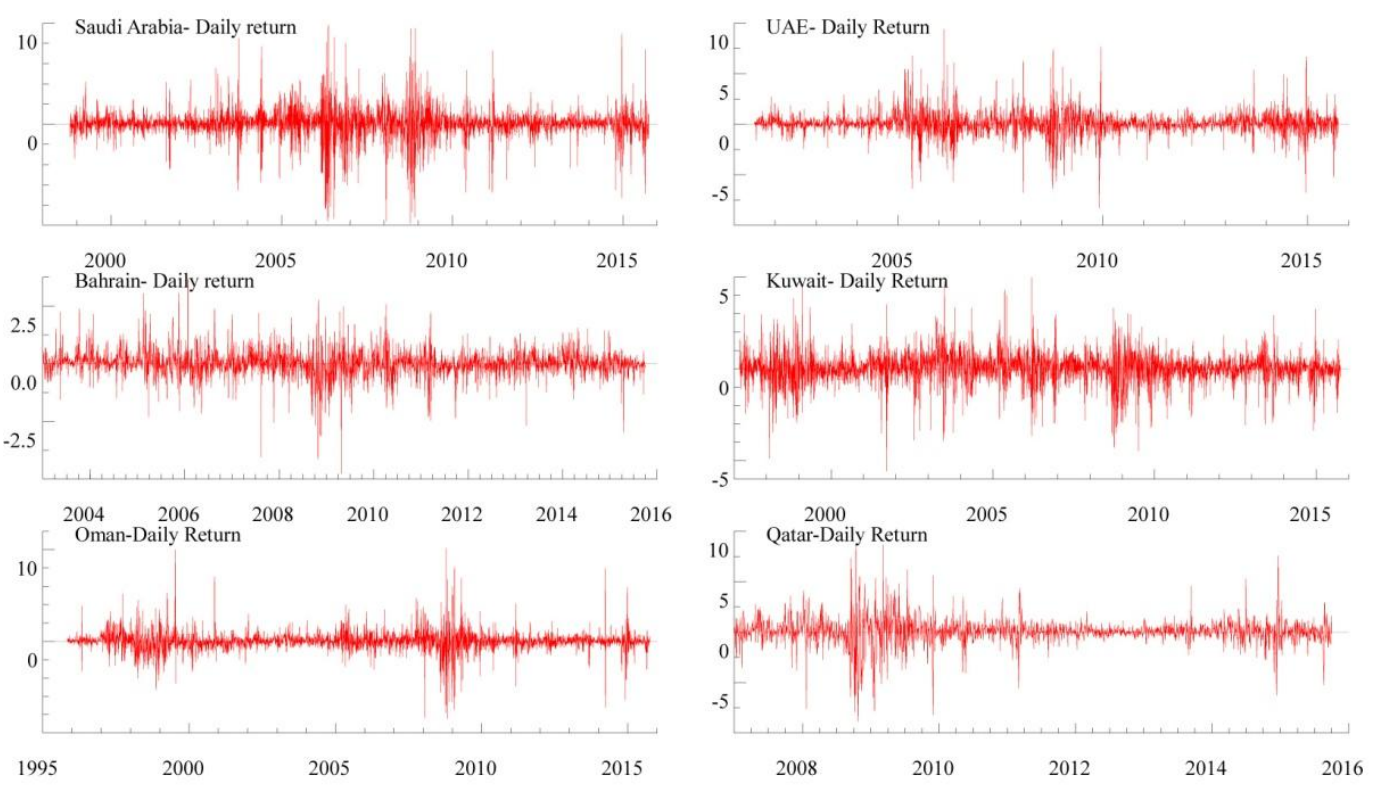

Figure 2. Daily percentage returns for all GCC countries 
Descriptive statistics for the daily returns are summarized in Table 1. It shows that Omani stock markets have the largest number of observations (4862) whereas, Qatar has the lowest number of observation (2194). The Qatar markets show the highest mean returns, Bahrain stock market shows the lowest daily returns, as well as the lowest spread of return. The Saudi market shows the highest spread of returns. Secondly, all indexes demonstrate a positive but close to zero sample mean, which is very minor when compared to the variable's standard deviation.

GCC markets show that the return distribution are not normal with fat tails, this is been supported by the result of Jarque-Bera test, skewness and kurtosis statistics. Furthermore, the market return of most GCC are skewed to the left, except UAE and Oman are skewed to the right indicates that non-symmetric behavior is exist. Additionally, all market returns show high levels of kurtosis specifying that these distributions have thicker tails than the normal distribution. The rejection of the Jarque-Bera test further confirms that daily returns are not normal distributed.

On the other hand, Ljung-Box test are used to assess the null hypothesis of a white noise process. The result indicates that the null hypothesis of no serial correlation is rejected for all GCC market returns. Likewise, Figure 3. displays that the returns of all markets are serial dependent, however, this can be eliminated by fitting an AR(p) (Autoregressive) model. Lastly, the ARCH-LM test shows the existence of conditional heteroscedasticity in the GCC return series.

Table 1. Descriptive statistics of daily returns for all GCC countries

\begin{tabular}{|c|c|c|c|c|c|c|}
\hline & Bahrain & UAE & Kuwait & Oman & Qatar & KSA \\
\hline Obs & 3149 & 3718 & 4580 & 4862 & 2194 & 4554 \\
\hline Starting date & $02 / 01 / 2003$ & 01/07/2001 & 05/03/1997 & $01 / 11 / 1995$ & 03/01/2007 & 19/10/1998 \\
\hline Ending Date & $01 / 10 / 2015$ & $01 / 10 / 2015$ & $01 / 10 / 2015$ & $01 / 10 / 2015$ & $01 / 10 / 2015$ & $01 / 10 / 2015$ \\
\hline MIN & -4.7505 & -8.3013 & -5.5618 & -8.4197 & -8.8077 & -9.813 \\
\hline MAX & 3.6935 & 9.3962 & 4.9766 & 10.133 & 8.6961 & 9.8458 \\
\hline Mean & 0.0081 & 0.0463 & 0.0244 & 0.0325 & 0.0594 & 0.0445 \\
\hline std.dev & 0.5813 & 1.124 & 0.8372 & 1.0116 & 1.3088 & 1.4282 \\
\hline Skewness & $-0.4396 * *$ & $0.1511^{* *}$ & $-0.4458 * *$ & $0.0543 * *$ & $-0.4180 * *$ & $-0.6442 * *$ \\
\hline Excess Kurtosis & $7.0255^{* *}$ & $9.5210^{* *}$ & $4.3765^{* *}$ & $16.9460 * *$ & $10.1560 * *$ & $10.3700^{* *}$ \\
\hline Jarque-Bera & $6577.6^{* *}$ & $14057 * *$ & $3806.9 * *$ & $58177 * *$ & $9493.7 * *$ & $20721 * *$ \\
\hline ARCH $1-10$ test & $16.296 * *$ & $70.199 * *$ & $76.249 * *$ & $138.52 * *$ & $61.954 * *$ & $116.10^{* *}$ \\
\hline ADF Statistics & $-29.118 * *$ & $-33.595 * *$ & $-35.156^{* *}$ & $-36.012 * *$ & $-24.594 * *$ & $-37.779 * *$ \\
\hline $\mathrm{Q}(10)$ & $103.86^{* *}$ & $211.664 * *$ & $1608.37 * *$ & $2272.72 * *$ & $1423.67 * *$ & $2820.59 * *$ \\
\hline d parameter (Geweke and Porter-Hudak (1983) & $0.0903^{*}$ & $0.1506^{*}$ & $0.1069^{*}$ & $0.1006^{*}$ & $0.0868 *$ & $0.0234^{*}$ \\
\hline d parameter (Robinson and Henry, 1998) & $0.1001 *$ & $0.1354 *$ & $0.1027 *$ & $0.1038^{*}$ & $0.0831 *$ & $0.0161 *$ \\
\hline
\end{tabular}
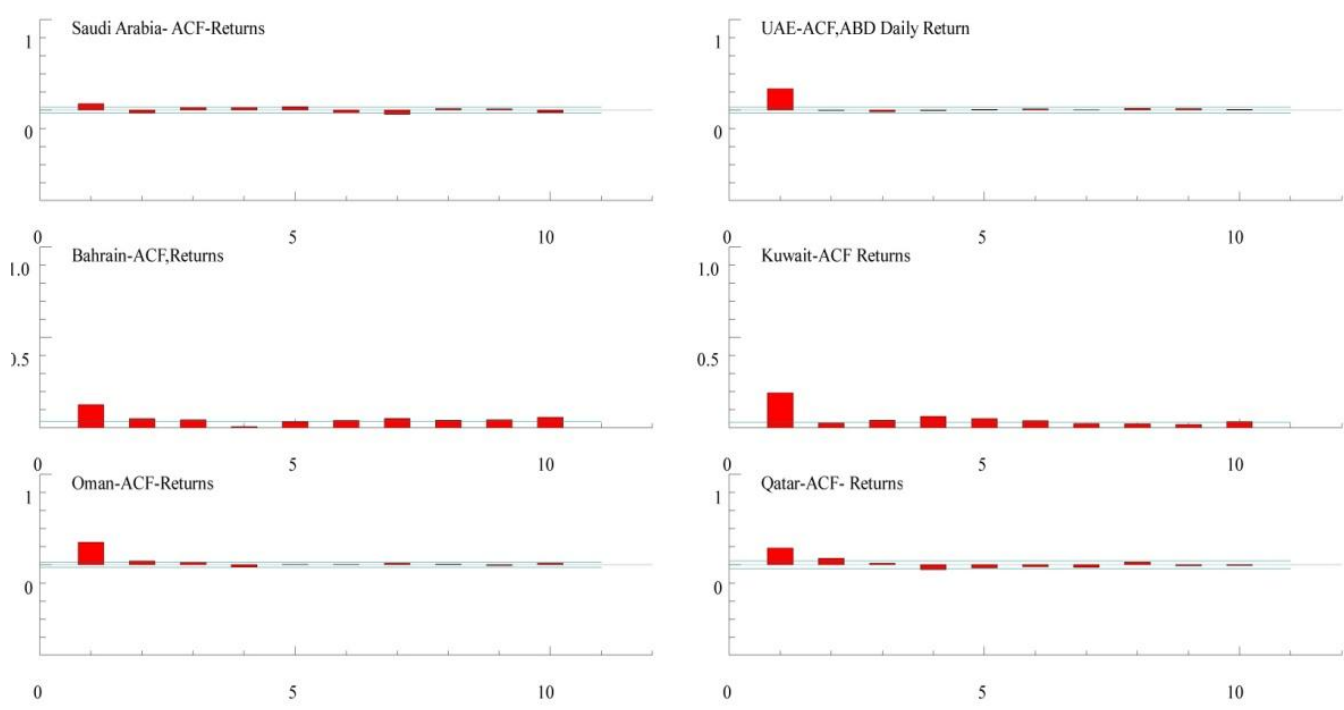

Figure 3. ACF of daily returns for all GCC Countries 
An AR model was fitted for each return series to remove any serial correlation in the series. The following specifications were estimated:

- AR(1) for United Arab Emeritus ;

- AR(2) for Qatar;

$-\mathrm{AR}(3)$ for Oman;

$-\mathrm{AR}(4)$ for Bahrain and Kuwait; and .

- AR(6) for Saudi Arabia.

Results are reported in Table 2 indicates that the residuals are non-normally distributed by the rejection of the Jarque-Bera test. Subsequently the Ljung-Box statistics are not significant for all GCC market returns; this indicates that these specifications are adequate to completely capture serial dependency in the market returns.

In addition, all GCC market returns show conditional heteroscedasticity since ARCH-LM tests are significant at $1 \%$. This supports the applying ARCH-type models to describe this feature of the data well.

Table 2. Residual analysis for the fitted AR(p) model for all GCC countries

\begin{tabular}{lllllll}
\hline & Bahrain & UAE & Kuwait & Oman & Qatar & Saudi Arabia \\
\hline MIN & -4.7336 & -8.4089 & -5.7096 & -9.2499 & -8.2822 & -10.147 \\
MAX & 3.626 & 9.3489 & 5.3373 & 12.039 & 8.947 & 9.9629 \\
Mean & $3.49 \mathrm{E}-08$ & $-7.65 \mathrm{E}-10$ & $7.36 \mathrm{E}-08$ & $-6.25 \mathrm{E}-10$ & $-1.77 \mathrm{E}-09$ & $-1.03 \mathrm{E}-08$ \\
std.dev & 0.57579 & 1.0924 & 0.81935 & 0.97922 & 1.2852 & 1.4203 \\
Skewness & $-0.40322^{* *}$ & $0.39434^{* *}$ & $-0.17740^{* *}$ & $0.12947^{* *}$ & $-0.12448^{* *}$ & $-0.53710^{* *}$ \\
Excess Kurtosis & $6.6870^{* *}$ & $9.6407^{* *}$ & $4.6829^{* *}$ & $20.153^{* *}$ & $9.6436^{* *}$ & $10.380^{* *}$ \\
Jarque-Bera & $5952.5^{* *}$ & $14495 . * *$ & $4208.9^{* *}$ & $82294 . * *$ & $8507.4^{* *}$ & $20665^{* *}$ \\
ARCH 1-10 test & $15.994^{* *}$ & $65.470^{* *}$ & $60.984^{* *}$ & $116.64^{* *}$ & $71.228^{* *}$ & $113.37^{* *}$ \\
Q(10) & 17.475 & 16.8984 & 8.17692 & 15.1712 & 14.4307 & 13.4998 \\
\hline
\end{tabular}

\section{Empirical results}

The different models are successively assessed by: (i) review and evaulation of model parameters and (ii) an assessment of model forecasting performance.

\subsection{Parameter Based Evaluation}

Tables 2, 3 and 4, present the parameter values and associated significance tests for the FIGARCH BBM, FIGARCH Chung, FIEGARCH FIAPRCH BBM, FIAPRCH Chung and HYGARCH specified model sets of all countries. United Arab Emirates (UAE), Bahrain, Kuwait, Oman, Qatar and Kingdom of Saudi Arabia (KSA).

For most countries and models, the constants in the mean parameter are positive and statistically significant. The exceptions were for Bahrain, where the constants are not statistically significant for all models. The constants in the variance equations parameter for Kuwait, Oman, and KSA are positive (except for FIEGARCH, which is are negative in all countries) and statistically significant for all models. For UAE, the constants in the variance equations, is positive and statistically significant only for FIGARCH BBM model. For Bahrain, it is positive and statistically significant for FIGARCH BBM, FIGARCH Chung, and FIEGARCH, and for Qatar is not statistically significant for FIEGARCH, FIGARCH BBM, and HYGARCH.

The $d$-FIGARCH coefficient for all models is statistically significant at the $99 \%$ confidence level in all countries, indicating the existence of long memory.

The ARCH coefficient (alpha) in Bahrain, Kuwait, and Qatar for all models is statistically significant at the 99\% level of confidence. This implies the existence of the ARCH process in the residuals term. The returns exhibit time-varying volatility clustering; this indicates that periods of volatility are followed by periods of relative calm. However this is not the case for other countries. For example, in KSA all models show that the alpha coefficient is not statistically significant. The GARCH coefficient (beta) is larger than the ARCH term (alpha) in all model sets (except for FIEGARCH in Bahrain, Oman, and Qatar). This is a further indication that the conditional variance will exhibit long persistence in volatility. Furthermore, the sum of alpha and beta1 is less than unity for all countries except for Bahrain and Qatar, which indicates stationary models in most countries.

The EGARCH coefficients (Theta1, and Theta2) are statistically significant at the $99 \%$ level of confidence in the magnitude effect and sign effect for all countries (except for sign effect in Bahrain, and Oman). 
The FIAPRCH coefficients (Gemma1, and Delta) are different than zero and 2 for BBM and Chung models and statistically significant at the $99 \%$ level of confidence for all countries (except Gemma1 in Bahrain and Oman are not significant). Furthermore, Gemma1 >0, implies that negative shocks give rise to higher volatility than positive shocks, for most countries except for Bahrain. As well as, delta of returns indicates that there is a predictable structure in the volatility pattern.

The HYGARCH coefficients (Log Alpha) are more than zero and statistically significant at the $99 \%$ level of confidence for three countries only, being the UAE, Oman, and KSA. This implies that the process is not stationary in the HYGARCH model and therefore, component observed are not restricted by covariance stationary.

Table 3. The frictional integration models set for all GCC countries

\begin{tabular}{|c|c|c|c|c|c|c|c|c|c|c|c|c|}
\hline & Model & & Cst(M) & $\operatorname{Cst}(V)$ & d-Figarch & Phi1 & Beta1 & Theta1 & Theta2 & Gamma1 & Delta & Log Alpha \\
\hline \multirow{12}{*}{ UAE } & FIGARCH BBM & Coefficient & 0.0543 & 0.019 & 0.5431 & 0.285 & 0.5315 & & & & & \\
\hline & & t-prob & 0 & 0.0241 & 0 & 0.001 & 0 & & & & & \\
\hline & FIGARCH Chung & Coefficient & 0.0562 & 0.3332 & 0.4191 & 0.2322 & 0.3816 & & & & & \\
\hline & & t-prob & 0 & 0.0724 & 0 & 0.091 & 0.016 & & & & & \\
\hline & FIEGARCH & Coefficient & 0.0359 & -1.3111 & 0.5104 & -0.3946 & 0.6406 & -0.0507 & 0.5234 & & & \\
\hline & & t-prob & 0.0023 & 0.0921 & 0 & 0.0163 & 0 & 0.0097 & 0 & & & \\
\hline & FIAPRCH BBM & Coefficient & 0.0511 & 0.0191 & 0.5645 & 0.2679 & 0.5212 & & & 0.1227 & 2.0861 & \\
\hline & & $\mathrm{t}$-prob & 0.0001 & 0.1046 & 0 & 0.0018 & 0 & & & 0.0012 & 0 & \\
\hline & FIAPRCH Chung & Coefficient & 0.0545 & 0.273 & 0.4536 & 0.1591 & 0.3013 & & & 0.1089 & 2.2364 & \\
\hline & & t-prob & 0 & 0.2245 & 0 & 0.4509 & 0.2391 & & & 0.0029 & 0 & \\
\hline & HYGARCH & Coefficient & 0.0533 & 0.0051 & 0.5068 & 0.3105 & 0.5219 & & & & & 0.1532 \\
\hline & & t-prob & 0 & 0.5854 & 0 & 0.004 & 0 & & & & & 0.0035 \\
\hline \multirow{12}{*}{ Bahrain } & FIGARCH BBM & Coefficient & 0.0155 & 0.0099 & 0.4565 & 0.5846 & 0.777 & & & & & \\
\hline & & t-prob & 0.1274 & 0.0775 & 0 & 0 & 0 & & & & & \\
\hline & FIGARCH Chung & Coefficient & 0.0165 & 0.2264 & 0.364 & 0.6284 & 0.7692 & & & & & \\
\hline & & $\mathrm{t}$-prob & 0.1004 & 0.0132 & 0 & 0 & 0 & & & & & \\
\hline & FIEGARCH & Coefficient & 0.0108 & -1.6254 & 0.5825 & 0.7187 & -0.6386 & 0.033 & 0.4306 & & & \\
\hline & & t-prob & 0.2072 & 0.0169 & 0 & 0.0021 & 0.0273 & 0.1846 & 0 & & & \\
\hline & FIAPRCH BBM & Coefficient & NA & NA & 0.3967 & 0.6715 & 0.8139 & & & -0.0945 & 2.2656 & \\
\hline & & t-prob & NA & NA & 0 & 0 & 0 & & & 0.083 & 0 & \\
\hline & FIAPRCH Chung & Coefficient & NA & NA & 0.3854 & 0.7243 & 0.8363 & & & -0.0944 & 2.33 & \\
\hline & & t-prob & NA & NA & 0 & 0 & 0 & & & 0.0727 & 0 & \\
\hline & HYGARCH & Coefficient & 0.0172 & -0.0013 & 0.3122 & 0.7355 & 0.835 & & & & & 0.2766 \\
\hline & & t-prob & 0.0991 & 0.7517 & 0.0035 & 0 & 0 & & & & & 0.0803 \\
\hline \multirow{12}{*}{ Kuwait } & FIGARCH BBM & Coefficient & 0.0415 & 0.017 & 0.6358 & 0.2768 & 0.6481 & & & & & \\
\hline & & t-prob & 0.0004 & 0.0002 & 0 & 0 & 0 & & & & & \\
\hline & FIGARCH Chung & Coefficient & 0.0422 & 1.1204 & 0.5082 & 0.2981 & 0.5599 & & & & & \\
\hline & & $\mathrm{t}$-prob & 0.0003 & 0.0254 & 0 & 0 & 0 & & & & & \\
\hline & FIEGARCH & Coefficient & 0.0249 & -2.015 & 0.1603 & -0.4813 & 0.9303 & -0.1055 & 0.4444 & & & \\
\hline & & $\mathrm{t}$-prob & 0.0403 & 0 & 0.1851 & 0 & 0 & 0 & 0 & & & \\
\hline & FIAPRCH BBM & Coefficient & 0.0273 & 0.0364 & 0.6406 & 0.2727 & 0.6508 & & & 0.2576 & 1.523 & \\
\hline & & t-prob & 0.0364 & 0.0005 & 0 & 0 & 0 & & & 0 & 0 & \\
\hline & FIAPRCH Chung & Coefficient & 0.03 & 1.3631 & 0.4618 & 0.3051 & 0.5094 & & & 0.2429 & 1.8245 & \\
\hline & & $\mathrm{t}$-prob & 0.0179 & 0.0087 & 0 & 0 & 0 & & & 0 & 0 & \\
\hline & HYGARCH & Coefficient & 0.0414 & 0.0166 & 0.6303 & 0.2785 & 0.6451 & & & & & 0.0033 \\
\hline & & t-prob & 0.0004 & 0.0022 & 0 & 0 & 0 & & & & & 0.907 \\
\hline \multirow{6}{*}{ Oman } & FIGARCH BBM & Coefficient & 0.0422 & 0.0334 & 0.669 & 0.0239 & 0.3563 & & & & & \\
\hline & & t-prob & 0.0001 & 0.0229 & 0 & 0.907 & 0.2207 & & & & & \\
\hline & FIGARCH Chung & Coefficient & NA & NA & 0.4983 & 0.0348 & 0.2419 & & & & & \\
\hline & & t-prob & NA & NA & 0 & 0.7678 & 0.0568 & & & & & \\
\hline & FIEGARCH & Coefficient & NA & -3.0388 & 0.5753 & 0.5023 & -0.2008 & -0.009 & 0.5487 & & & \\
\hline & & t-prob & NA & 0 & 0 & 0.0143 & 0.3893 & 0.5414 & 0 & & & \\
\hline
\end{tabular}




\begin{tabular}{|c|c|c|c|c|c|c|c|c|c|c|c|c|}
\hline & FIAPRCH BBM & Coefficient & 0.0409 & 0.055 & 0.6098 & 0.0798 & 0.3863 & & & 0.0113 & 1.5533 & \\
\hline & & t-prob & 0.0001 & 0.0102 & 0 & 0.6549 & 0.1174 & & & 0.7246 & 0 & \\
\hline & FIAPRCH Chung & Coefficient & NA & NA & 0.5164 & 0.008 & 0.2183 & & & -0.0294 & 2.0761 & \\
\hline & & t-prob & NA & NA & 0 & 0.9465 & 0.0841 & & & 0.3064 & 0 & \\
\hline & HYGARCH & Coefficient & 0.0422 & 0.0282 & 0.6728 & 0.0061 & 0.3541 & & & & & 0.1097 \\
\hline & & $\mathrm{t}$-prob & 0.0001 & 0.037 & 0 & 0.9798 & 0.2749 & & & & & 0.0257 \\
\hline \multirow{12}{*}{ Qatar } & FIGARCH BBM & Coefficient & 0.0572 & 0.0214 & 0.5864 & 0.409 & 0.6566 & & & & & \\
\hline & & t-prob & 0.0005 & 0.0583 & 0 & 0.0002 & 0 & & & & & \\
\hline & FIGARCH Chung & Coefficient & 0.0571 & 3.0544 & 0.5506 & 0.4072 & 0.6222 & & & & & \\
\hline & & t-prob & 0.0005 & 0.0452 & 0 & 0.0021 & 0 & & & & & \\
\hline & FIEGARCH & Coefficient & 0.0564 & -0.4743 & 0.6304 & 0.6269 & -0.7381 & -0.0818 & 0.5793 & & & \\
\hline & & t-prob & 0.0003 & 0.5906 & 0 & 0 & 0 & 0.0026 & 0 & & & \\
\hline & FIAPRCH BBM & Coefficient & 0.0517 & 0.0289 & 0.5747 & 0.3717 & 0.6362 & & & 0.1505 & 1.8603 & \\
\hline & & t-prob & 0.002 & 0.064 & 0 & 0.0018 & 0 & & & 0.0024 & 0 & \\
\hline & FIAPRCH Chung & Coefficient & 0.0518 & 3.2194 & 0.5263 & 0.3668 & 0.5884 & & & 0.1577 & 1.8538 & \\
\hline & & t-prob & 0.0021 & 0.0205 & 0 & 0.0188 & 0.0009 & & & 0.0019 & 0 & \\
\hline & HYGARCH & Coefficient & 0.0556 & 0.0177 & 0.5811 & 0.4263 & 0.6627 & & & & & 0.0422 \\
\hline & & t-prob & 0.0009 & 0.1095 & 0 & 0.0004 & 0 & & & & & 0.3539 \\
\hline \multirow{12}{*}{ KSA } & FIGARCH BBM & Coefficient & 0.0705 & 0.0518 & 0.5257 & 0.0126 & 0.3108 & & & & & \\
\hline & & t-prob & 0 & 0.0004 & 0 & 0.9007 & 0.0082 & & & & & \\
\hline & FIGARCH Chung & Coefficient & NA & NA & 0.4727 & 0.1565 & 0.4118 & & & & & \\
\hline & & t-prob & NA & NA & 0 & 0.3887 & 0.04 & & & & & \\
\hline & FIEGARCH & Coefficient & 0.0555 & -1.3672 & 0.4814 & -0.1268 & 0.6025 & -0.1056 & 0.4118 & & & \\
\hline & & t-prob & 0.0001 & 0.0507 & 0 & 0.5455 & 0 & 0 & 0 & & & \\
\hline & FIAPRCH BBM & Coefficient & 0.0563 & 0.0622 & 0.5158 & -0.0023 & 0.2855 & & & 0.2506 & 1.9108 & \\
\hline & & t-prob & 0 & 0.0009 & 0 & 0.9819 & 0.0157 & & & 0 & 0 & \\
\hline & FIAPRCH Chung & Coefficient & 0.0587 & 1.8596 & 0.484 & -0.0304 & 0.2251 & & & 0.2359 & 1.9883 & \\
\hline & & t-prob & 0 & 0.0018 & 0 & 0.7708 & 0.0448 & & & 0 & 0 & \\
\hline & HYGARCH & Coefficient & 0.0681 & 0.0404 & 0.5192 & -0.0091 & 0.2991 & & & & & 0.1009 \\
\hline & & $\mathrm{t}$-prob & 0 & 0.0084 & 0 & 0.9324 & 0.0131 & & & & & 0.0212 \\
\hline
\end{tabular}

In order to identify the most capable model from the groups that have been tested, the diagnostic tests of the standardized residuals used and presented in Table 4 below; included Log likelihood, Akaike information criteria, $\operatorname{ARCH}(10)$ and $Q 2(10)$ statistics.

The result of the diagnostic tests of the standardized residuals for both $\mathrm{ARCH}(10)$ and $Q 2(10)$ statistics specify that heteroscedasticity has been fully accounted for by the models. Furthermore, For all countries (except Kuwait, and KSA), $\log$ likelihood and Akaike tests indicate that the FIEGARCH model produces the best performance. However, for Kuwait and KSA, the FIAPRCH BBM model produces the best performance.

In fact, Log-likelihood values can not be used unaccompanied as a directory of fit for the reason that they are a function of sample size nonetheless it can be used to compare the fit of different coefficients.

Whereas, Akaike's Information Criterion is an index used in selecting econometric models, it is defined as:

$$
-2 L_{m}+2 m
$$

Where:

$L_{m}$ is the maximized log-likelihood

$m$ is the number of parameters in the model.

Akaike's Information Criterion takes into consideration both the statistical goodness of fit and the number of parameters that have to be valued to reach this specific degree of fit by forcing a penalty for adding up more parameters. On the other hand, lower values of the Akaike's Information Criterion specifies the favored model, that is, the one with the fewest parameters that still provides an adequate fit to the data.

To end with, Log likelihood and Akaike information criteria based tests all have nearly similar results for all models. This proposes they offer minimal help in differentiating between model sets, this rise the needed of alternative forecasting-based testing procedures to apply. 
Table 4. The diagnostic tests of the standardized residuals for all GCC countries

\begin{tabular}{|c|c|c|c|c|c|c|}
\hline & Model & & Log Likelihood & Akaike & $\mathrm{Q}(10)$ & $\mathrm{ARCH}(10)$ \\
\hline \multirow{12}{*}{ UAE } & \multirow{2}{*}{ FIGARCH BBM } & Coefficient & -4344 & 2.3411 & 3.4406 & 0.3527 \\
\hline & & t-prob & & & 0.9037 & 0.9661 \\
\hline & \multirow{2}{*}{ FIGARCH Chung } & Coefficient & -4337.8 & 2.3377 & 2.653 & 0.2678 \\
\hline & & t-prob & & & 0.9542 & 0.988 \\
\hline & \multirow{2}{*}{ FIEGARCH } & Coefficient & -4322.3 & 2.3305 & 3.5823 & 0.3672 \\
\hline & & t-prob & & & 0.8927 & 0.9608 \\
\hline & \multirow{2}{*}{ FIAPRCH BBM } & Coefficient & -4337.6 & 2.3387 & 3.8666 & 0.3938 \\
\hline & & t-prob & & & 0.869 & 0.95 \\
\hline & \multirow{2}{*}{ FIAPRCH Chung } & Coefficient & -4330.3 & 2.3347 & 3.4874 & 0.3515 \\
\hline & & t-prob & & & 0.9002 & 0.9665 \\
\hline & \multirow{2}{*}{ HYGARCH } & Coefficient & -4338.1 & 2.3384 & 4.9719 & 0.5121 \\
\hline & & t-prob & & & 0.7606 & 0.8828 \\
\hline \multirow{12}{*}{ Bahrain } & \multirow{2}{*}{ FIGARCH BBM } & Coefficient & -2159.3 & 1.3784 & 9.9138 & 0.9781 \\
\hline & & t-prob & & & 0.2711 & 0.4602 \\
\hline & \multirow{2}{*}{ FIGARCH Chung } & Coefficient & -2159.78 & 1.3787 & 9.0076 & 0.8911 \\
\hline & & t-prob & & & 0.3417 & 0.5407 \\
\hline & \multirow{2}{*}{ FIEGARCH } & Coefficient & -2148.58 & 1.3729 & 5.4869 & 0.5377 \\
\hline & & t-prob & & & 0.7045 & 0.8644 \\
\hline & \multirow{2}{*}{ FIAPRCH BBM } & Coefficient & -2162.04 & 1.3801 & 6.9748 & 0.6898 \\
\hline & & t-prob & & & 0.5394 & 0.735 \\
\hline & \multirow{2}{*}{ FIAPRCH Chung } & Coefficient & -2159.67 & 1.3786 & 6.0077 & 0.595 \\
\hline & & t-prob & & & 0.6464 & 0.8193 \\
\hline & \multirow{2}{*}{ HYGARCH } & Coefficient & -2154.57 & 1.376 & 9.2745 & 0.9294 \\
\hline & & t-prob & & & 0.3197 & 0.5047 \\
\hline \multirow{12}{*}{ Kuwait } & \multirow{2}{*}{ FIGARCH BBM } & Coefficient & -4640.7 & 2.0313 & 4.8193 & 0.4859 \\
\hline & & $\mathrm{t}$-prob & & & 0.7767 & 0.9003 \\
\hline & \multirow{2}{*}{ FIGARCH Chung } & Coefficient & -4642.75 & 2.0322 & 4.7708 & 0.4742 \\
\hline & & t-prob & & & 0.7818 & 0.9076 \\
\hline & \multirow{2}{*}{ FIEGARCH } & Coefficient & -4625.28 & 2.0255 & 5.4055 & 0.5552 \\
\hline & & t-prob & & & 0.7135 & 0.8513 \\
\hline & FIAPRCH BBM & Coefficient & -4618.54 & 2.0225 & 5.5812 & 0.5651 \\
\hline & FIAРКСН ВВIМ & t-prob & & & 0.694 & 0.8436 \\
\hline & FIAPRCH Chung & Coefficient & -4621.87 & 2.024 & 6.552 & 0.6562 \\
\hline & FIAPKCHCNUng & t-prob & & & 0.5857 & 0.7659 \\
\hline & HYGARCH & Coefficient & -4640.69 & 2.0317 & 4.8579 & 0.4899 \\
\hline & ПНОАКС & t-prob & & & 0.7727 & 0.8977 \\
\hline & FIGARCH BBM & Coefficient & -4595.9 & 1.8947 & 1.5736 & 0.1579 \\
\hline & FIUAKC П DDIVI & t-prob & & & 0.9914 & 0.9987 \\
\hline & FIGARCH Chung & Coefficient & -4619.03 & 1.9033 & 1.1836 & 0.1174 \\
\hline & 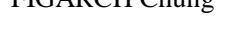 & t-prob & & & 0.9968 & 0.9996 \\
\hline & FIEGARCH & Coefficient & -4554.95 & 1.8782 & 1.2932 & 0.1291 \\
\hline Oman & FIEUAKCH & t-prob & & & 0.9956 & 0.9995 \\
\hline Uman & FIAPRCH BBM & Coefficient & -4589.37 & 1.8928 & 1.5578 & 0.1542 \\
\hline & ГIATKC D DDVI & t-prob & & & 0.9917 & 0.9988 \\
\hline & FIAPRCH Chung & Coefficient & -4617.74 & 1.9032 & 1.1221 & 0.1114 \\
\hline & ГІАГКС П СIUII & t-prob & & & 0.9974 & 0.9997 \\
\hline & HYGARCH & Coefficient & -4591.69 & 1.8933 & 1.8469 & 0.1869 \\
\hline & ПТОАКС & t-prob & & & 0.9854 & 0.9972 \\
\hline & FIGARCH BRM & Coefficient & -2803.97 & 2.5642 & 5.5154 & 0.5247 \\
\hline & FIUARCH BВIV & t-prob & & & 0.7013 & 0.8738 \\
\hline Oatar & FIGARCH Chung & Coefficient & -2802.98 & 2.5633 & 5.5158 & 0.5281 \\
\hline Q palal & ГТОАКС П СIUI & t-prob & & & 0.7013 & 0.8714 \\
\hline & FIFGARCH & Coefficient & -2795.6 & 2.5584 & 7.6891 & 0.7605 \\
\hline & ГIEUAKС & t-prob & & & 0.4644 & 0.6673 \\
\hline
\end{tabular}




\begin{tabular}{|c|c|c|c|c|c|c|}
\hline & \multirow{2}{*}{ FIAPRCH BBM } & Coefficient & -2798.8 & 2.5613 & 6.2819 & 0.5931 \\
\hline & & t-prob & & & 0.6157 & 0.8208 \\
\hline & \multirow{2}{*}{ FIAPRCH Chung } & Coefficient & -2797.54 & 2.5602 & 6.2524 & 0.5959 \\
\hline & & t-prob & & & 0.619 & 0.8184 \\
\hline & \multirow{2}{*}{ HYGARCH } & Coefficient & -2803.48 & 2.5641 & 5.7186 & 0.5467 \\
\hline & & t-prob & & & 0.6787 & 0.8576 \\
\hline \multirow{12}{*}{ KSA } & \multirow{2}{*}{ FIGARCH BBM } & Coefficient & -6111.47 & 2.6897 & 2.9418 & 0.2995 \\
\hline & & t-prob & & & 0.938 & 0.9815 \\
\hline & \multirow{2}{*}{ FIGARCH Chung } & Coefficient & -6148.28 & 2.705 & 2.5571 & 0.2438 \\
\hline & & t-prob & & & 0.959 & 0.9917 \\
\hline & \multirow{2}{*}{ FIEGARCH } & Coefficient & -6089.39 & 2.6809 & 3.1706 & 0.3156 \\
\hline & & t-prob & & & 0.9232 & 0.9775 \\
\hline & \multirow{2}{*}{ FIAPRCH BBM } & Coefficient & -6087.27 & 2.68 & 2.9876 & 0.3038 \\
\hline & & t-prob & & & 0.9351 & 0.9805 \\
\hline & \multirow{2}{*}{ FIAPRCH Chung } & Coefficient & -6089.43 & 2.6809 & 2.6364 & 0.2672 \\
\hline & & t-prob & & & 0.9551 & 0.9881 \\
\hline & \multirow{2}{*}{ HYGARCH } & Coefficient & -6108.48 & 2.6888 & 3.1581 & 0.3241 \\
\hline & & t-prob & & & 0.9241 & 0.9751 \\
\hline
\end{tabular}

\subsection{Forecasting Based Evaluation}

The Superior Predictive Ability test applied to evaluate the performance of two or more forecasting models. Forecasts are assessed using a pre-specified loss function using the 'best' forecast model presence the one generating the minimum expected loss. A significant concern that researchers have to identify what the loss function is assessed in contradiction of; therefore, this research classify losses are assessed comparative to the observed returns. For that reason, Mean Squared Error (MSE) and Mean Absolute Deviation (MAD) are used as loss functions for SPA.

In this paper, we benchmarked against a random walk. The result, presented in Table 6 below, shows that the FIGARCH BBM produces the smallest loss and is therefore the best fitting model for UAE, Bahrain, KSA, and Oman. Whereas, FIEGARCH produces the smallest loss and is therefore the best fitting model for Kuwait, and FIGARCH Chung the best fitting model for Qatar.

Table 5. Superior predictive ability tests for all GCC countries

\begin{tabular}{|c|c|c|c|c|c|c|c|c|}
\hline & \multicolumn{4}{|c|}{ UAE } & \multicolumn{4}{|c|}{ Bahrain } \\
\hline & Model Number & Sample Loss & t-stat & "p-value" & Model Number & Sample Loss & t-stat & "p-value" \\
\hline Most Significant & StdRes-H & 0.410 & 14.545 & 0.000 & StdRes-H & 0.187 & 8.169 & 0.000 \\
\hline Best & StdRes-BBM & 0.390 & 14.180 & 0.000 & StdRes-H & 0.187 & 8.169 & 0.000 \\
\hline Model_25\% & StdRes-E & 0.402 & 14.285 & 0.000 & StdRes-E & 0.216 & 6.194 & 0.000 \\
\hline Median & StdRes-Chung & 0.404 & 13.501 & 0.000 & StdRes-Chung & 0.233 & 5.801 & 0.000 \\
\hline Model_75\% & StdRes-H & 0.410 & 14.545 & 0.000 & StdRes-P-BBM & 0.255 & 4.227 & 0.000 \\
\hline \multirow[t]{2}{*}{ Worst } & StdRes-P-Chung & 0.424 & 13.814 & 0.000 & StdRes-P-BBM & 0.284 & 2.865 & 0.003 \\
\hline & \multicolumn{4}{|c|}{$\mathrm{KSA}$} & \multicolumn{4}{|c|}{ Kuwait } \\
\hline Most Significant & StdRes-P-BBM & 0.723 & 19.145 & 0.000 & StdRes-HY & 0.211 & 17.703 & 0.000 \\
\hline Best & StdRes-BBM & 0.685 & 18.657 & 0.000 & StdRes-E & 0.208 & 17.542 & 0.000 \\
\hline Model_25\% & StdRes-E & 0.708 & 18.880 & 0.000 & StdRes-HY & 0.211 & 17.703 & 0.000 \\
\hline Median & StdRes-Chung & 0.712 & 17.736 & 0.000 & StdRes-BBM & 0.211 & 17.695 & 0.000 \\
\hline Model_75\% & StdRes-P-BBM & 0.723 & 19.145 & 0.000 & StdRes-P-BBM & 0.218 & 17.662 & 0.000 \\
\hline \multirow[t]{2}{*}{ Worst } & StdRes-P-Chung & 0.732 & 19.039 & 0.000 & StdRes-P-Chung & 0.225 & 17.309 & 0.000 \\
\hline & \multicolumn{4}{|c|}{ Oman } & \multicolumn{4}{|c|}{ Qatar } \\
\hline Most Significant & StdRes-HY & 0.457 & 12.422 & 0.000 & StdRes-P-BBM & 0.562 & 12.429 & 0.000 \\
\hline Best & StdRes-P-BBM & 0.451 & 11.650 & 0.000 & StdRes-Chung & 0.553 & 12.264 & 0.000 \\
\hline Model_25\% & StdRes-E & 0.456 & 11.701 & 0.000 & StdRes-BBM & 0.554 & 12.287 & 0.000 \\
\hline Median & StdRes-HY & 0.457 & 12.422 & 0.000 & StdRes-P-BBM & 0.562 & 12.429 & 0.000 \\
\hline Model_75\% & StdRes-P-Chung & 0.518 & 10.311 & 0.000 & StdRes-HY & 0.568 & 12.399 & 0.000 \\
\hline Worst & StdRes-Chung & 0.528 & 9.983 & 0.000 & StdRes-E & 0.577 & 12.226 & 0.000 \\
\hline
\end{tabular}


Model Confidence Set (MCS) procedure can also be used to evaluate the best forecasting models. Since it applies the same loss function as SPA but not required benchmark, in fact it classifies efficient model sets at different levels of confidence (Hansen \& Lunde, 2014).

The results of the MCS presented in Table 7 and identify that the FIGARCH BBM is $90 \%$ confidence model set for the UAE, Bahrain, and KSA. Whereas, FIAPARCH BBM for Oman, FIEGARCH for Kuwait, and FIGARCH Chung for Qatar. This finding is consisting with SPA early in this section, with the exception of Oman.

Table 6. Model confidence set tests for all GCC countries

\begin{tabular}{|c|c|c|c|c|c|}
\hline \multicolumn{4}{|c|}{ UAE } & \multicolumn{2}{|c|}{ Bahrain } \\
\hline Model Name & $\operatorname{mse}\left(* 10^{\wedge} 3\right)$ & MCS p-val. & Model Name & $\mathrm{mse}\left(* 10^{\wedge} 3\right)$ & MCS p-val. \\
\hline NoChange & 1.26588 & 0 & NoChange & 0.33843 & 0 \\
\hline FIGARCH BBM & 0.38997 & $1.0000^{*}$ & FIGARCH BBM & 0.18657 & $1.0000^{*}$ \\
\hline FIGARCH Chung & 0.40414 & 0.0529 & FIGARCH Chung & 0.28391 & 0 \\
\hline FIEGARCH & 0.40209 & 0.0813 & FIEGARCH & 0.21561 & 0 \\
\hline FIAPRCH BBM & 0.40597 & 0.0003 & HYGARCH & 0.23319 & 0 \\
\hline FIAPRCH Chung & 0.42428 & 0.0004 & FIAPRCH BBM & 0.25511 & 0 \\
\hline HYGARCH & 0.40986 & 0.0002 & FIAPRCH Chung & 0.24963 & 0 \\
\hline \multicolumn{4}{|c|}{ KSA } & \multicolumn{2}{|c|}{ Oman } \\
\hline NoChange & 2.04372 & 0 & NoChange & 1.02502 & 0 \\
\hline FIGARCH BBM & 0.68489 & $1.0000^{*}$ & FIGARCH BBM & 0.46265 & 0.0014 \\
\hline FIEGARCH & 0.7077 & 0.0019 & FIAPRCH BBM & 0.45135 & $1.0000^{*}$ \\
\hline FIAPRCH BBM & 0.72264 & 0 & HYGARCH & 0.45716 & $0.5969^{*}$ \\
\hline FIAPRCH Chung & 0.73153 & 0 & FIGARCH Chung & 0.52759 & 0 \\
\hline HYGARCH & 0.72003 & 0 & FIAPRCH Chung & 0.51814 & 0 \\
\hline FIGARCH Chung & 0.71207 & 0.0051 & FIEGARCH & 0.45637 & $0.5969^{*}$ \\
\hline \multicolumn{4}{|c|}{ Kuwait } & \multicolumn{2}{|c|}{ Qatar } \\
\hline NoChange & 0.7015 & 0 & NoChange & 1.71786 & 0 \\
\hline FIGARCH BBM & 0.21146 & $0.1297 *$ & FIGARCH BBM & 0.55382 & $0.5632 *$ \\
\hline FIGARCH Chung & 0.21684 & 0.0003 & FIGARCH Chung & 0.5534 & $1.0000^{*}$ \\
\hline FIEGARCH & 0.20808 & $1.0000^{*}$ & FIEGARCH & 0.57673 & 0.0304 \\
\hline FIAPRCH BBM & 0.21843 & 0.0003 & FIAPRCH BBM & 0.56192 & $0.1040^{*}$ \\
\hline FIAPRCH Chung & 0.22466 & 0 & FIAPRCH Chung & 0.56193 & $0.1040^{*}$ \\
\hline HYGARCH & 0.21135 & $0.3747 *$ & HYGARCH & 0.56849 & 0 \\
\hline
\end{tabular}

\section{Discussion of Findings and Conclusions}

Given the enormous dissimilarities between developed countries and GCC markets, it is perhaps a little astonishing that the outcome of this research, regarding to UAE, Bahrain, KSA, and Oman, are similar with earlier researches made of developed markets. For example, Bentes (2014) studied the G7 markets and detected that FIGARCH BBM is the best appropriate model.

Further similarities can be identified between our results and other studies. Aloui and Hela Ben (2014) investigated the long memory, asymmetry and structural breaks using VaR for the period 2003 to 2013. The forecasting result of out-of-sample testing indicates that FIAPRCH provided the best predictive ability. Their work, in respect to the GCC countries, concluded that Saudi Arabia and Oman exhibit long memory in the mean and variance equations. However, the rest of the countries show long memory only in variance equations.

The significant variability of results encountered in these dissimilar studies proposes that it is challenging to determine there is a 'one size fits all' model that can be used to model long memory affects in stock market returns.

We believe that our study contributes significantly to the literature by evaluating the difference models of Fractionally Integrated-GARCH Models (FIGARCH BBM's, FIGARCH Chung, FIEGARCH, FIAPARCH BBM's, FIAPARCH Chung, and HYGARCH). Most researches compare one of Fractionally Integrated-GARCH Models with the traditional GARCH, EGARCH, GJG-GARCH, IGARCH, and APGARCH.

Both Superior Predictive Ability and Model Confidence Set results identify that FIGARCH BBM is the best 
fitting model for UAE, KSA, and Bahrain. FIEGARCH is the best fitting model for Kuwait. FIGARCH Chung is the best fitting model for Qatar. Only Oman's results were a combination of the FIGARCH BBM and FIAPARCH BBM models.

\section{References}

Al-Hajieh, H. (2015). Behavioral of Islamic Financial Markets: The Case of Asymmetric Behavioral of 17 Countries. International Journal of Economics, Commerce and Management, 3(7). Retrieved from http://ijecm.co.uk/volume-iii-issue-7/

Al-Hajieh, H., Redhead, K., \& Rodgers, T. (2011). Investor sentiment and calendar anomaly effects: A case study of the impact of Ramadan on Islamic Middle Eastern markets. Research in International Business and Finance, 25(3), 345-356. https://doi.org/10.1016/j.ribaf.2011.03.004

Aloui, C., \& H. Hela ben (2014). Modelling and forecasting value at risk and expected shortfall for GCC stock markets: Do long memory, structural breaks, asymmetry, and fat-tails matter? The North American Journal of Economics and Finance, 29(C), 349-380. https://doi.org/10.1016/j.najef.2014.06.006

Assaf, A. (2016). MENA stock market volatility persistence: Evidence before and after the financial crisis of 2008. Research in International Business and Finance, 36(C), 222-240. https://doi.org/10.1016/j.ribaf.2015.09.003

Baillie, R., Bollerslev, T., \& Mikkelsen, H. (1996). Fractionally integrated generalized autoregressive conditional heteroskedasticity. Journal of Econometrics, 74(1), 3-30. https://doi.org/10.1016/S0304-4076(95)01749-6

Bentes, S. R. (2014). Measuring persistence in stock market volatility using the FIGARCH approach. Physica A: Statistical Mechanics and Its Applications, 408(C), 190-197. https://doi.org/10.1016/j.physa.2014.04.032

Bentes, S. R., \& Ferreira, N. B. (2013). A FIGARCH approach to stock market volatility: Evidence from Portugal, Ireland, Italy, Greece and Spain. International Journal of Academic Research, 5(6), 107-111. https://doi.org/10.7813/2075-4124.2013/5-6/A.14

Bollerslev, T., \& Mikkelsen, H. (1996). Modeling and pricing long memory in stock market volatility. Journal of Econometrics, 73, 151-184. https://doi.org/10.1016/0304-4076(95)01736-4

Boubaker, H., \& Sghaier, N. (2015). Semiparametric generalized long-memory modeling of some mena stock market returns: A wavelet approach. Economic Modelling, 50(C), 254-265. https://doi.org/10.1016/j.econmod.2015.06.027

Chung, C. (1999). Estimating a generalized long memory process. Journal of Econometrics, 73(1), 237-259. https://doi.org/10.1016/0304-4076(95)01739-9

Conrad, C. (2010). Non-negativity conditions for the hyperbolic GARCH model. Journal of Econometrics, 157, 441-457. https://doi.org/10.1016/j.jeconom.2010.03.045

Conrad, C., \& Haag, B. (2006). Inequality constraints in the fractionally integrated garch model. Journal of Financial Econometrics, 4, 413-449. https://doi.org/10.1093/jjfinec/nbj015

Davidson, J. (2004). Moment and memory properties of linear conditional heteroscedasticity models, and a new model. Journal of Business \& Economic Statistics, 22(1), 16-29. https://doi.org/10.1198/073500103288619359

Hansen, P. (2005). A test for superior predictive ability. Journal of Business \& Economic Statistics, 23, 365-380. http://dx.doi.org/10.1198/073500105000000063

Hansen, P. R., \& Lunde, A. (2014). Estimating the persistence and the autocorrelation function of a time series that is measured with error. Econometric Theory, 30(01), 60-93. https://doi.org/10.1017/S0266466613000121

Hansen, P., Lunde, A., \& Nason, J. (2011). The model confidence set. Econometrica, 79, 453-497. https://doi.org/10.3982/ECTA5771

Kumar, D. (2013). Asymmetric long memory volatility in the PIIGS economies. Review of Accounting and Finance, 12(1), 23-43. http://dx.doi.org/10.1108/14757701311295818

Li, M., Li, G., \& Li, W. (2011). Score tests for hyperbolic GARCH models. Journal of Business \& Economic Statistics, 29(4), 579-586. http://dx.doi.org/10.1198/jbes.2011.10024

Li, M., WK. L., \& Li, G. (2015). A new hyperbolic GARCH model. Journal of Econometrics, 189, 428-436. https://doi.org/10.1016/j.jeconom.2015.03.034 
Robinson, P., \& Zaffaroni, P. (2006). Pseudo-maximum likelihood estimation of ARCH( $\infty)$ models. The Annals of Statistics, 34(3), 1049-1074. https://doi.org/10.1214/009053606000000245

Tse, Y. (1998). The conditional heteroscedasticity of the yen-dollar exchange rate. Journal of Applied Econometrics, $13(1)$ 49-55. https://doi.org/10.1002/(SICI)1099-1255(199801/02)13:1<49::AID-JAE459>3.0.CO;2-O

\section{Copyrights}

Copyright for this article is retained by the author(s), with first publication rights granted to the journal.

This is an open-access article distributed under the terms and conditions of the Creative Commons Attribution license (http://creativecommons.org/licenses/by/4.0/). 